\title{
Anti-proliferative activity of epigallocatechin-3-gallate and silibinin on soft tissue sarcoma cells
}

\author{
KAMRAN HARATI $^{1}$, BJÖRN BEHR ${ }^{1}$, CHRISTOPH WALLNER $^{1}$, ADRIEN DAIGELER ${ }^{1}$, TOBIAS HIRSCH ${ }^{1}$, \\ FRANK JACOBSEN $^{1}$, MARCUS RENNER ${ }^{2}$, ALI HARATI ${ }^{3}$, MARCUS LEHNHARDT ${ }^{1}$ and MUSTAFA BECERIKLI $^{1}$ \\ ${ }^{1}$ Department of Plastic Surgery, Burn Center, Hand Center, Sarcoma Reference Center, \\ BG-University Hospital Bergmannsheil, D-44789 Bochum; ${ }^{2}$ Institute of Pathology, University of Heidelberg, \\ D-69120 Heidelberg; ${ }^{3}$ Department of Neurosurgery, Klinikum Dortmund, D-44145 Dortmund, Germany
}

Received July 24, 2016; Accepted October 26, 2016

DOI: $10.3892 / \mathrm{mmr} .2016 .5969$

\begin{abstract}
Disseminated soft tissue sarcomas (STS) present a therapeutic dilemma. The first-line cytostatic doxorubicin demonstrates a response rate of $30 \%$ and is not suitable for elderly patients with underlying cardiac disease, due to its cardiotoxicity. Well-tolerated alternative treatment options, particularly in palliative situations, are rare. Therefore, the present study assessed the anti-proliferative effects of the natural compounds epigallocatechin-3-gallate (EGCG), silibinin and noscapine on STS cells. A total of eight different human STS cell lines were used in the study: Fibrosarcoma (HT1080), liposarcoma (SW872, T778 and MLS-402), synovial sarcoma (SW982, SYO1 and 1273) and pleomorphic sarcoma (U2197). Cell proliferation and viability were analysed by 5-bromo-2'-deoxyuridine and MTT assays and real-time cell analysis (RTCA). RTCA indicated that noscapine did not exhibit any inhibitory effects. By contrast, EGCG decreased proliferation and viability of all cell lines except for the 1273 synovial sarcoma cell line. Silibinin exhibited anti-proliferative effects on all synovial sarcoma, liposarcoma and fibrosarcoma cell lines. Liposarcoma cell lines responded particularly well to EGCG while synovial sarcoma cell lines were more sensitive to silibinin. In conclusion, the green tea polyphenol EGCG and the natural flavonoid silibinin from milk thistle suppressed the proliferation and viability of liposarcoma, synovial sarcoma and fibrosarcoma cells. These compounds are therefore potential candidates as mild therapeutic options for patients that are not suitable for doxorubicin-based chemotherapy and require palliative treatment. The findings from the present study provide evidence
\end{abstract}

Correspondence to: Dr Kamran Harati, Department of Plastic Surgery, Burn Center, Hand Center, Sarcoma Reference Center, BG-University Hospital Bergmannsheil, 1 Bürkle de la Camp-Platz, D-44789 Bochum, Germany

E-mail:kamran.harati@t-online.de

Key words: soft tissue sarcoma, synovial sarcoma, liposarcoma, fibrosarcoma, epigallocatechin, silibinin to support in vivo trials assessing the effect of these natural compounds on solid sarcomas.

\section{Introduction}

Soft tissue sarcomas (STS) are a heterogeneous group of solid tumours arising from transformed cells of mesenchymal origin. They may occur throughout the body and represent $\sim 1 \%$ of all adult malignancies (1). In patients with primary diagnosed STS without distant metastasis, standard treatment involves surgical resection with negative margins, typically followed by adjuvant radiation to decrease the risk of recurrence $(2,3)$. However, almost half of all patients with STS develop distant metastases, rendering them unsuitable for surgery $(4,5)$. If metastasis has occurred, the median survival time regardless of chemotherapeutic treatment is $<12$ months $(6,7)$. A limited number of chemotherapeutic agents, including doxorubicin and ifosfamide, are effective for the treatment of metastatic STS (2). However, the response rates of these agents are poor and often do not result in significant extension of survival (8). Doxorubicin is the predominant chemotherapeutic agent used for the treatment of metastatic STS, and has a response rate of $\sim 30 \%$ (9,10). The combination of doxorubicin and ifosfamide exhibits greater response rates compared with doxorubicin alone; however, it is associated with severe short- and long-term adverse effects, including bone marrow suppression and cardiomyopathy (11-13).

A multicentre analysis by the European Organisation for Research and Treatment of Cancer (trial 62012) on 455 patients with advanced STS indicated that an intensified combination treatment with doxorubicin and ifosfamide is not suitable for treatment of locally advanced or metastatic STS as a result of the serious adverse effects, and should therefore only be used with a view to tumour shrinkage (13). Furthermore, the versatility of doxorubicin is limited by dose-associated and cumulative myocardial toxicity, particularly in older patients with a history of cardiac disease (14). However, the incidence of STS increases markedly $>50$ years of age, when the prevalence of cardiac diseases is also greater (15). Currently, there are no efficacious and safe agents for the palliative treatment of patients who may not undergo doxorubicin-based chemotherapy due to underlying cardiac disease. Therefore, the 
development of novel therapeutic agents is required for the treatment of STS.

A review of the literature reveals various potential well-tolerated and natural phytochemicals that exhibit anti-neoplastic effects on malignant cells, including the compounds epigallocatechin-3-gallate (EGCG), silibinin and noscapine. EGCG is the most abundant catechin in green tea and demonstrates anti-inflammatory, antioxidant and antineoplastic activities (16-18). Various in vitro studies have revealed that EGCG exhibits anticancer activity in lung (19), prostate (20), colon (21), gastric (22), breast (23) and cervical carcinoma cells (24). To date, EGCG has undergone various phase II trials and has been demonstrated to be well-tolerated following oral administration (25-29). The most frequent adverse reactions observed were gastrointestinal reactions, including nausea and vomiting. In rare cases, patients presented with elevated serum alanine aminotransferase levels following the administration of high doses of oral EGCG; however, liver function tests returned to baseline following discontinuation of ECGC (30). Therefore, EGCG is considered to be a safe and well-tolerated agent for the treatment of cancer patients $(31,32)$.

Silibinin is the primary active constituent of silymarin, a standardized extract from the seeds of the milk thistle plant (Silybum marianum). Silibinin is available as a therapeutic agent in various European countries and is used for the treatment of toxic liver damage, particularly due to Amanita phalloides intoxication (33). It is well tolerated in cancer patients $(34,35)$ and has demonstrated anti-neoplastic effects in various malignant cell lines including HT1080 fibrosarcoma cells (36-40).

Noscapine is a naturally occurring opium alkaloid and a widely used antitussive drug that is non-addictive and has a low toxicity profile (41). As a tubulin-binding agent, various preclinical studies have established its tumour-inhibitory effects in a wide range of malignancies (42-45). Currently, noscapine is undergoing phase II clinical trials for cancer chemotherapy (46).

Based on these results, the present study aimed to investigate the anti-proliferative activity of EGCG, silibinin and noscapine on eight different STS cell lines, including fibrosarcoma, liposarcoma, synovial sarcoma and pleomorphic sarcoma cells.

\section{Materials and methods}

Cell lines. Eight different human STS cell lines were used in the present study: HT1080 (fibrosarcoma), SW872 (liposarcoma), T778 (liposarcoma), MLS-402 (liposarcoma), SW982 (synovial sarcoma), SYO1 (synovial sarcoma), 1273 (synovial sarcoma) and U2197 (pleomorphic sarcoma/malignant fibrous histiocytoma). HT1080, SW872 and SW982 were purchased from CLS Cell Lines Service GmbH (Eppelheim, Germany) and were cultured in Dulbecco's modified Eagle's medium (DMEM; PAN-Biotech GmbH, Aidenbach, Germany) supplemented with $10 \%$ foetal bovine serum (FBS; Thermo Fisher Scientific, Inc., Waltham, MA, USA), $1 \%$ penicillin (100 U/ml) and 1\% streptomycin (100 $\mu \mathrm{g} / \mathrm{ml}$; PAN-Biotech $\mathrm{GmbH})$. The well-differentiated T778 liposarcoma cell line and the MLS-402 myxoid liposarcoma cell line were donated by Professor Pierre Åman (University of Gothenburg,
Gothenburg, Sweden) and Professor Ola Myklebost (Oslo University Hospital, Oslo, Norway), respectively. T778 and MLS-402 cells were cultured in RPMI (PAN-Biotech GmbH) supplemented with $10 \%$ FBS and $1 \%$ penicillin/streptomycin as previously described $(47,48)$. The SYO-1 and 1273 cell lines were donated by Dr Akira Kawai (National Cancer Center, Tokyo, Japan) and Professor Olle Larsson (Karolinska Institutet, Stockholm, Sweden) (49,50). The SYO-1 cells were cultured in DMEM supplemented with $10 \%$ FBS, $1 \%$ penicillin/streptomycin and $0.5 \%$ sodium pyruvate. The 1273 cells were cultivated in Ham's F12 (PAN-Biotech GmbH) supplemented with $10 \%$ FBS and $1 \%$ penicillin/streptomycin. The U2197 cell line was obtained from the German Collection of Microorganisms and Cell Cultures (Braunschweig, Germany) and was cultured in minimum essential medium (PAN-Biotech $\mathrm{GmbH}$ ) supplemented with $20 \%$ FBS, $0.165 \%$ sodium bicarbonate and $1 \%$ penicillin/streptomycin (51). All cultures were maintained at $37^{\circ} \mathrm{C}$ in a humidified $5 \% \mathrm{CO}_{2}$ atmosphere.

Phytotherapeutic agents. EGCG, silibinin and noscapine were obtained from Sigma-Aldrich; Merck Millipore (Darmstadt, Germany). The stock solution was dissolved in dimethyl sulfoxide (DMSO; Carl Roth GmbH \& Co. KG, Karlsruhe, Germany) and further diluted in DMEM to concentrations of $50 \mu \mathrm{M}$ (EGCG), $150 \mu \mathrm{M}$ (silibinin) and $30 \mu \mathrm{M}$ (noscapine) for all assays. These concentrations have been demonstrated to inhibit proliferation and induce apoptosis in various malignant cell lines $(36,52,53)$.

Cell viability assay. Metabolic activity was measured using an MTT assay. Cells were seeded in 96-well plates (Corning Incorporated, Corning, NY, USA) at $1 \times 10^{4}$ cells per well. The following day, the three agents were added in the aforementioned concentrations for $24 \mathrm{~h}$. Subsequently, $50 \mu 10.5 \mathrm{mg} / \mathrm{ml}$ MTT (Sigma-Aldrich; Merck Millipore) was added for $4 \mathrm{~h}$. MTT is a yellow dye that is reduced to purple formazan in the mitochondria of vital cells. Cells were lysed following the addition of $200 \mu \mathrm{l}$ DMSO and $25 \mu \mathrm{l}$ glycine buffer (containing $0.1 \mathrm{M}$ glycine and $0.1 \mathrm{M} \mathrm{NaCl}$, adjusted to $\mathrm{pH} 10.5$ with $\mathrm{NaOH}$ ) per well. The quantity of integrated dye represented the level of metabolism and was measured at a wavelength of $562 \mathrm{~nm}$ using an Elx808 Ultra Microplate Reader (BioTek Instruments GmbH, Bad Friedrichshall, Germany).

Proliferation assay. To quantify the effects of EGCG, silibinin and noscapine on cell proliferation, a colorimetric cell proliferation 5-bromo-2'-deoxyuridine (BrdU)-ELISA assay (Roche Diagnostics $\mathrm{GmbH}$, Mannheim, Germany) was performed according to the manufacturer's protocol. Briefly, cells were seeded at $1 \times 10^{4}$ cells/well in 96-well plates and cultured for $24 \mathrm{~h}$. The phytotherapeutic agents were subsequently added in the appropriate concentrations for $24 \mathrm{~h}$. The BrdU labelling solution was added and incubated for a further $24 \mathrm{~h}$. BrdU, a pyrimidine analogue, integrates into the DNA of proliferating cells. The level of proliferation was quantified by the light emission detected via an Orion Microplate Luminometer (Berthold Detection Systems GmbH, Pforzheim, Germany). Cell proliferation was determined in quadruplicate. The results are expressed as a percentage of the proliferation of DMSO-treated control cells. 
Table I. Summary of the cytostatic effects of EGCG, silibinin and noscapine, as assessed by MTT and BrdU assays and RTCA.

\begin{tabular}{|c|c|c|c|c|c|c|c|c|c|c|}
\hline \multirow[b]{2}{*}{ Subtype } & \multirow[b]{2}{*}{ Cell line } & \multicolumn{3}{|c|}{ EGCG } & \multicolumn{3}{|c|}{ Silibinin } & \multicolumn{3}{|c|}{ Noscapine } \\
\hline & & MTT & BrdU & RTCA & MTT & BrdU & RTCA & MTT & BrdU & RTCA \\
\hline Fibrosarcoma & HT1080 & + & + & + & + & + & + & + & + & - \\
\hline \multirow[t]{3}{*}{ Liposarcoma } & SW872 & + & + & + & + & - & + & + & + & - \\
\hline & T778 & + & + & + & + & + & + & + & + & - \\
\hline & MLS-402 & + & + & + & + & + & + & + & - & - \\
\hline \multirow[t]{3}{*}{ Synovial sarcoma } & SW982 & + & + & + & + & + & + & + & + & - \\
\hline & SYO1 & - & + & + & + & + & + & + & - & - \\
\hline & 1273 & + & + & - & + & + & + & + & + & + \\
\hline Pleomorphic sarcoma & U2197 & + & + & + & + & + & - & - & + & - \\
\hline
\end{tabular}

+, cytostatic effect; -, no cytostatic effect. EGCG, epigallocatechin-3-gallate; BrdU, 5-bromo-2'-deoxyuridine; RTCA, real-time cell analysis.

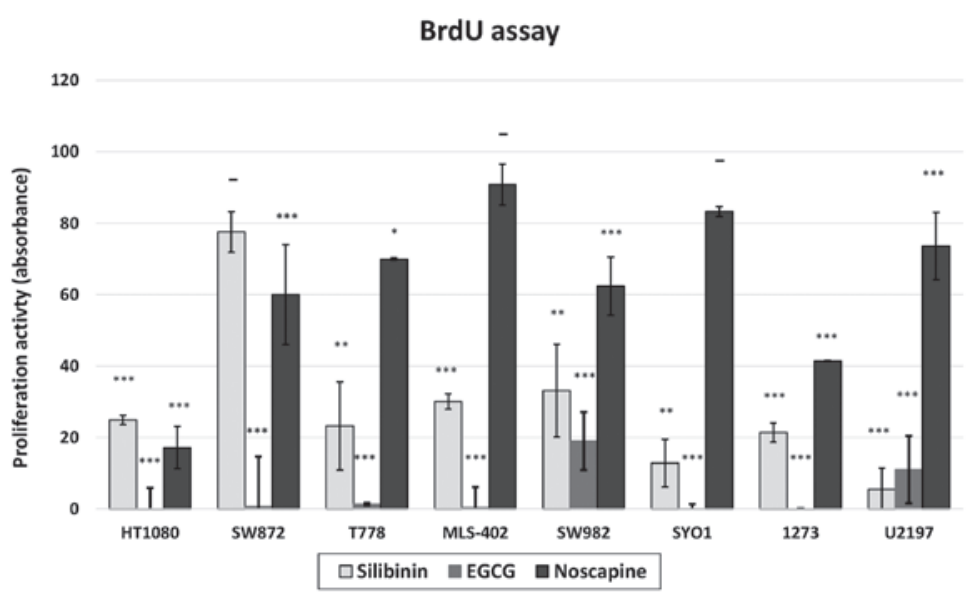

Figure 1. Effects of silibinin, ECGC and noscapine on cell proliferation. The proliferative activity of all cell lines was measured by BrdU assay. The assay was performed following $24 \mathrm{~h}$ of treatment with DMSO, silibinin, ECGC or noscapine. For clarity, the BrdU-labelling index of the DMSO-treated control cells was adjusted to 100 for each cell line and is not included. The indices for the different treatment groups were subsequently calculated as follows: Index treatment group $\mathrm{i}=($ mean absorbance rate treatment group $\mathrm{i} \times 100) /$ mean absorbance rate DMSO control. Data are presented as the mean \pm standard deviation. $\mathrm{P}>0.05$, ${ }^{*} \mathrm{P}<0.05,{ }^{* *} \mathrm{P}<0.01$ and ${ }^{* * *} \mathrm{P}<0.001$ vs. DMSO-treated control cells. EGCG, epigallocatechin-3-gallate; BrdU, 5-bromo-2'-deoxyuridine; DMSO, dimethyl sulfoxide.

Real-time cell analysis (RTCA). Cells were seeded in two 8 -well plates with an integrated microelectronic sensor array in $600 \mu \mathrm{l}$ culture medium (iCELLigence Real Time Cell Analyser; ACEA Biosciences, San Diego, CA, USA). After $24 \mathrm{~h}$, the therapeutic agents were added for a total volume of $50 \mu 1$. The cell proliferation and survival were monitored in real-time by measuring the cell-to-electrode responses of the seeded cells. In each individual E-well, the cell impedance was measured and converted to cell index (CI) values by the RTCA software version 1.2 (Roche Diagnostics GmbH) (54). The graphs were generated in real-time by the iCELLigence system. Untreated and DMSO-treated cells served as controls.

Statistical analysis. Data analyses were performed using the statistical program SPSS 16 (SPSS, Inc., Chicago, IL, USA). Data are expressed as the mean \pm standard deviation. Comparisons between the experimental groups in BrdU and MTT assays were performed using one-way analysis of variance followed by post-hoc Tukey's test. $\mathrm{P}<0.05$ was considered to indicate a statistically significant difference.

\section{Results}

EGCG significantly inhibits the proliferation and viability of STS cell lines. As indicated by the BrdU assay, the proliferation of all eight human STS cell lines was inhibited by EGCG (Fig. 1). By MTT analysis, EGCG decreased the viability of seven cell lines (Fig. 2). To evaluate the proliferation and viability of cells continuously over a longer time period, RTCA was performed. The viability, adhesion and proliferation of the cells were monitored prior to and during EGCG treatment in real time for 160 h (Figs. 3-5). EGCG markedly decreased the CI of all STS cell lines except the 1273 synovial sarcoma cell line. The administration of EGCG reduced the CI of the HT1080 fibrosarcoma cell line and the U2197 pleomorphic sarcoma cell line (Fig. 3). All three liposarcoma cell lines (SW872, T778 and MLS-402) exhibited a continuously decreased CI during EGCG treatment compared with untreated or DMSO-treated cells (Fig. 4), as did the remaining two synovial sarcoma cells lines (SW982 and SYO1; Fig. 5). 


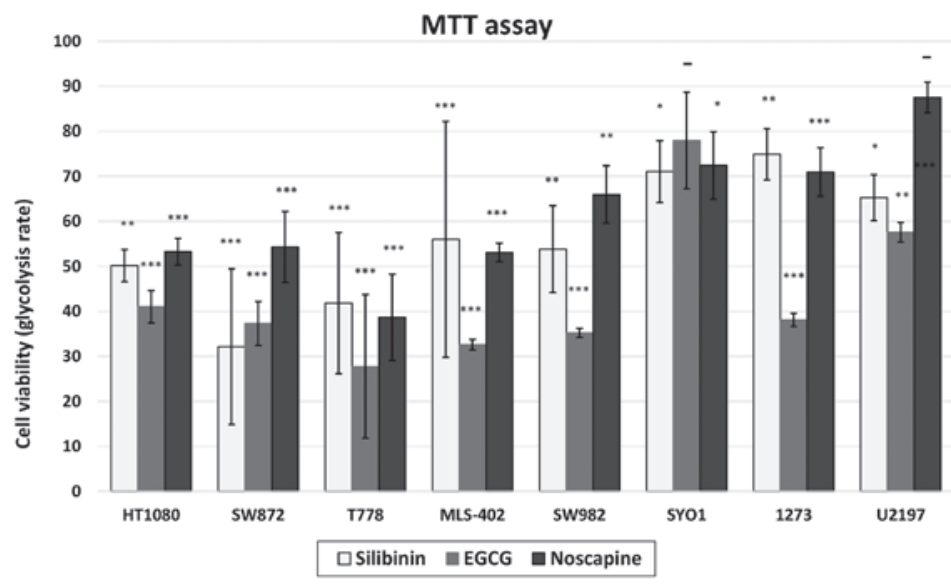

Figure 2. Effects of silibinin, ECGC and noscapine on cell viability. The cell viability of all cell lines was measured by MTT assay. The assay was performed following $24 \mathrm{~h}$ of treatment with DMSO, silibinin, ECGC or noscapine. For clarity, the MTT-index of the DMSO-treated control cells was adjusted to 100 for each cell line and is not included. The indices for the different treatment groups were subsequently calculated as follows: Index treatment group $\mathrm{i}=($ mean absorbance rate treatment group i $x 100) /$ mean absorbance rate DMSO control. Data are presented as the mean \pm standard deviation. ${ }^{-} \mathrm{P}>0.05,{ }^{*} \mathrm{P}<0.05,{ }^{* * *} \mathrm{P}<0.01$ and ${ }^{* * *} \mathrm{P}<0.001$ vs. DMSO-treated control cells. EGCG, epigallocatechin-3-gallate; DMSO, dimethyl sulfoxide.

Silibinin significantly decreases the proliferative activity and viability of STS cell lines. Treatment with silibinin significantly reduced the proliferation of seven STS cell lines (Fig. 1), and significantly decreased the cell viability of all eight assessed STS cell lines, as analysed by MTT assay (Fig. 2). By RTCA, silibinin was the only compound that exhibited a strong inhibitory effect on all three synovial sarcoma cells (Fig. 5). In addition, silibinin reduced the CI of all liposarcoma cell lines; however, not to the extent of EGCG. Only the U2197 pleomorphic sarcoma cell line did not respond to silibinin treatment.

By RTCA, STS cell lines are unaffected by noscapine treatment. Noscapine exhibited cytostatic effects on STS cells, as assessed using BrdU (Fig. 1) and MTT (Fig. 2) assays at $24 \mathrm{~h}$. However, these effects could not be validated by RTCA over a longer time period. The proliferation inhibition resulting from noscapine treatment in six cell lines at $24 \mathrm{~h}$ did not result in a continual decrease of the CI. In all cell lines, the CI of noscapine-treated cells increased steadily and was comparable to the $\mathrm{CI}$ of DMSO-treated or untreated control cells during the $160 \mathrm{~h}$ of real-time analysis (Figs. 3-5).

\section{Discussion}

STS are a heterogeneous group of rare mesenchymal malignancies. To date, systemic treatment options are limited following metastasis. Patients with distant metastases have a median survival time of less than one year despite systemic chemotherapy (6,7). Due to the infrequent and heterogeneous nature of STS the development of novel systemic therapeutic agents is challenging and novel chemotherapy strategies are lacking. Therefore, the development of well-tolerated and effective chemotherapeutic agents for the treatment of STS is required.

The present study assessed the cytostatic effects of the naturally occurring compounds noscapine, silibinin and EGCG on eight STS cell lines. By RTCA, noscapine did not exhibit any relevant anti-proliferative effects (Table I). In contrast, silibinin and EGCG exerted cytostatic effects in

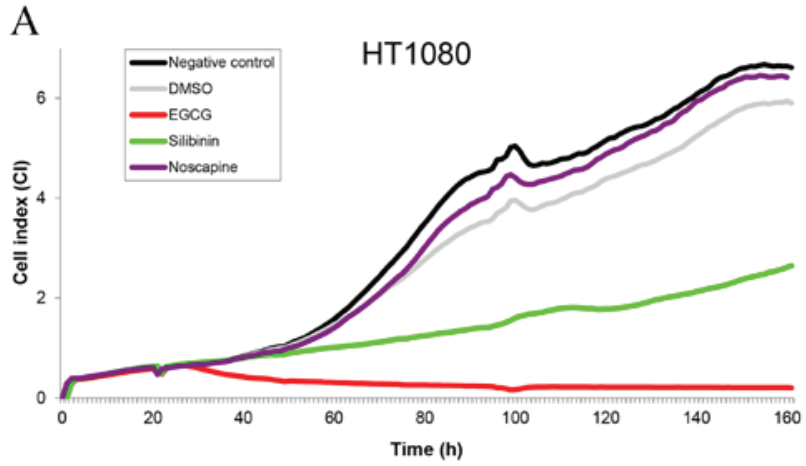

$\mathrm{B}$

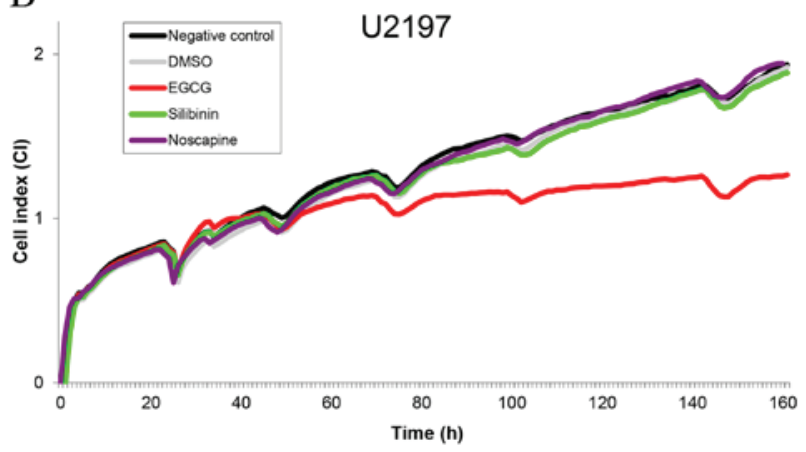

Figure 3. Real-time cell analysis of fibrosarcoma and malignant fibrous histiocytoma cells. (A) HT1080 fibrosarcoma cells and (B) U2197 pleomorphic sarcoma/malignant fibrous histiocytoma cells were seeded in 8-well plates with an integrated microelectronic sensor array. The CI reflecting the number of viable cells was monitored continuously in real-time. The compounds were applied to the wells after $24 \mathrm{~h}$ resulting in a bend of the CI curve as impedance measurements were transiently disrupted by the addition of the solutions. In EGCG-treated HT1080 cells, CI decreased and remained at a low level. Silibinin slightly decreased the CI of HT1080 cells. U2197 cells were unaffected by silibinin and responded only poorly to EGCG. EGCG, epigallocatechin-3-gallate; CI, cell index; DMSO, dimethyl sulfoxide.

almost all examined STS cell lines, as assessed by BrdU, MTT and RTCA. Administration of EGCG decreased proliferation and viability of all liposarcoma cell lines and two synovial sarcoma cell lines for more than five days. In addition, it 
A

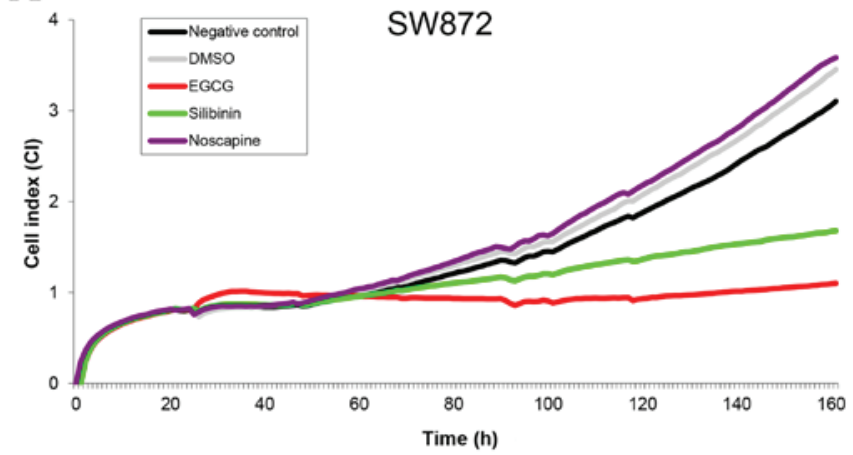

B

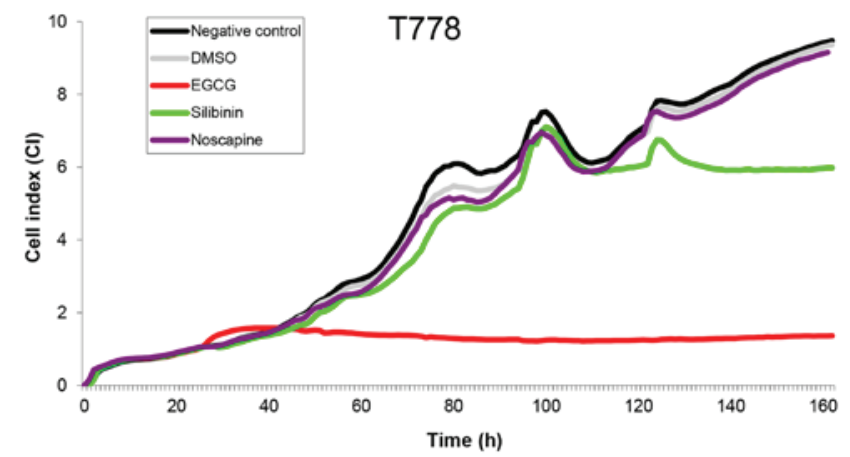

$\mathrm{C}$

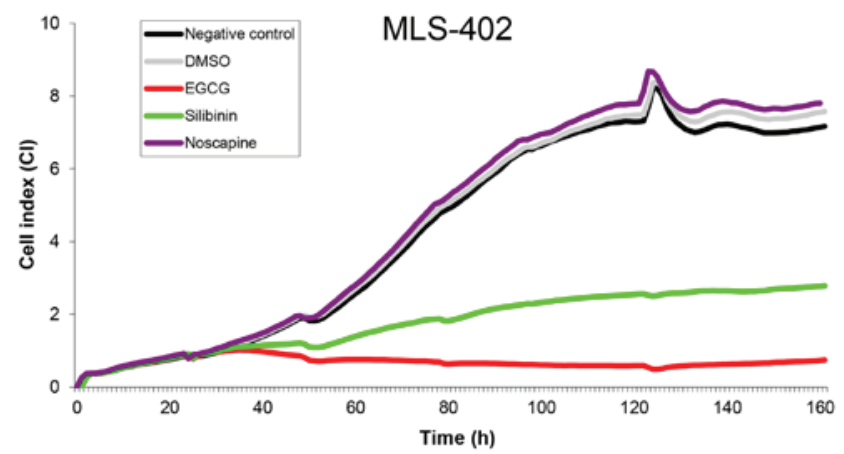

Figure 4. Real-time cell analysis of liposarcoma cell lines. (A) SW872, (B) T778 and (C) MLS-402 liposarcoma cells were seeded in 8-well plates with an integrated microelectronic sensor array. The $\mathrm{CI}$ reflecting the number of viable cells was monitored continuously in real-time. The compounds were applied to the wells after $24 \mathrm{~h}$ resulting in a bend of the CI curve as impedance measurements were transiently disrupted by the addition of the solutions. The CI curve of SW872 cells was slightly decreased by silibinin. T778 and MLS-402 cells exhibited a moderate response to silibinin, and a strong response to EGCG. EGCG, epigallocatechin-3-gallate; CI, cell index; DMSO, dimethyl sulfoxide.

inhibited HT1080 fibrosarcoma and U2197 pleomorphic sarcoma cells. Of the three analysed compounds, EGCG exerted the greatest anti-proliferative activity in the three assessed liposarcoma cell lines, rendering it a potential agent of interest. Liposarcomas represent the most frequent somatic STS subtype and respond poorly to anthracycline-based chemotherapy, with well-differentiated and de-differentiated tumours exhibiting response rates of only 12 and 13\%, respectively (55). Pleomorphic liposarcomas are the least responsive to chemotherapy, with a response rate of $5 \%$, whereas myxoid liposarcomas have been revealed to be the most sensitive to chemotherapy, exhibiting response rates of $44-48 \%$ (56-58). In the present study, EGCG exhibited a distinct inhibitory effect
A

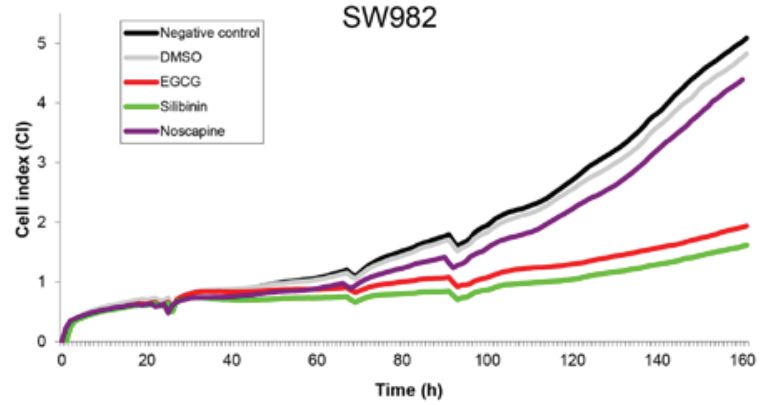

B

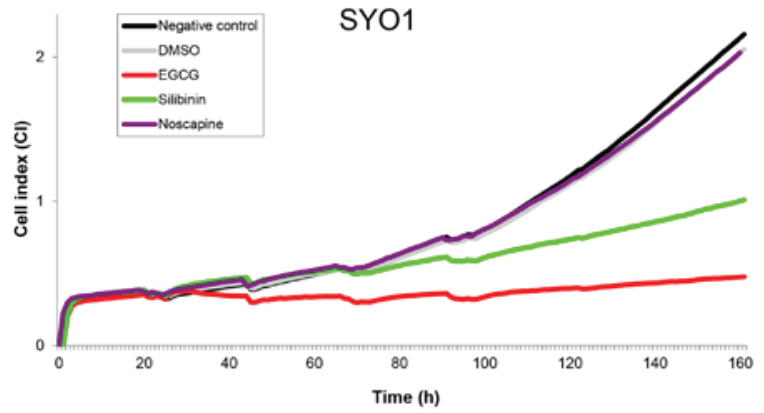

$\mathrm{C}$

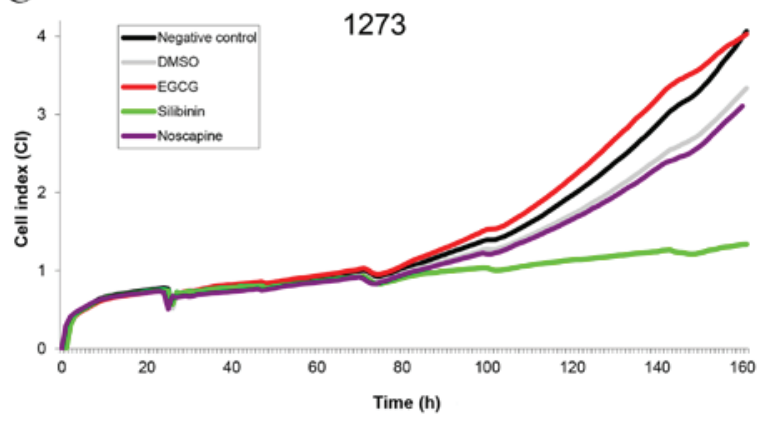

Figure 5. Real-time cell analysis of synovial sarcoma cell lines. (A) SW982, (B) SYO1 and (C) 1273 synovial sarcoma cells were seeded in 8-well plates with an integrated microelectronic sensor array. The $\mathrm{CI}$ reflecting the number of viable cells was monitored continuously in real-time. The compounds were applied to the wells after $24 \mathrm{~h}$ resulting in a bend of the CI curve as impedance measurements were transiently disrupted by the addition of the solutions. EGCG reduced the CI gradient of SW982 and SYO1 cells, but had no effect on 1273 cells. Silibinin markedly decreased the viability of all three synovial sarcoma cell lines. EGCG, epigallocatechin-3-gallate; CI, cell index; DMSO, dimethyl sulfoxide.

on T778 cells from a well-differentiated liposarcoma, SW872 cells from a pleomorphic liposarcoma and MLS-402 cells from a myxoid liposarcoma. Although these findings were in vitro, they suggested a potential anti-proliferative activity of EGCG on liposarcoma cells that should be further investigated in vivo.

In comparison with EGCG, the inhibitory effect of silibinin was reduced in liposarcoma cells, but greater in synovial sarcoma cells. Silibinin significantly decreased proliferation and viability in all three synovial sarcoma cell lines. Although synovial sarcomas have typically been considered relatively chemosensitive, the European Organisation for Research and Treatment of Cancer recently reported a chemotherapy response rate of only $28 \%$ for patients with advanced synovial sarcoma (59). Therefore, there remains a requirement for 
alternative cytostatic agents for the treatment for synovial sarcomas, and the in vitro effects of silibinin demonstrated in the present study should be further examined in vivo.

A literature review revealed that the green tea polyphenol EGCG has further notable properties. Various in vivo studies have confirmed that EGCG mitigates doxorubicin-induced cardiotoxicity by suppressing oxidative stress (60-63). The oxygen free radical scavenging ability of EGCG has been demonstrated to protect cardiomyocytes from doxorubicin-mediated cardiotoxicity according to histopathological analysis (64). Furthermore, EGCG has been revealed to synergistically enhance the anticancer activity of doxorubicin in various in vivo studies on prostate and liver cancer (65-67). Notably, similar chemosensitizing and chemopreventive activities have been described for silibinin; in vivo studies revealed that silibinin synergistically enhances the apoptosis-inducing activity of doxorubicin and ameliorates doxorubicin-induced cardiotoxicity (68-73). Therefore, EGCG and silibinin may additionally function as chemopreventives and chemosensitizers for doxorubicin, which remains the first-line cytostatic for the systemic treatment of disseminated STS.

In conclusion, the present in vitro study demonstrated that EGCG and silibinin inhibit the proliferation and viability of liposarcoma, synovial sarcoma, fibrosarcoma and pleomorphic sarcoma cells. Liposarcoma cell lines responded particularly well to EGCG while synovial sarcoma cell lines were more sensitive to silibinin. To the best of our knowledge, this is the first study to assess the effects of EGCG and silibinin on such a wide range of STS cell lines, including liposarcoma, synovial sarcoma, fibrosarcoma and pleomorphic sarcoma cells. EGCG and silibinin are not intended to supplant doxorubicin for the treatment of patients with disseminated STS; however, they may be a potential therapeutic option for patients who require palliative treatment but are considered unsuitable for chemotherapy. The present study provides evidence to support in vivo trials to examine the effects of these natural compounds on STS.

\section{Acknowledgements}

The present study was supported by a FoRUM grant from the Ruhr-University Bochum (Bochum, Germany; grant no. K090-15).

\section{References}

1. Hoos A, Lewis JJ and Brennan MF: Weichgewebssarkomeprognostische Faktoren und multimodale Therapie. Der Chirurg 71: pp787-794, 2000.

2. Patrikidou A, Domont J, Cioffi A and Le Cesne A: Treating soft tissue sarcomas with adjuvant chemotherapy. Curr Treat Options Oncol 12: 21-31, 2011.

3. Kaushal A and Citrin D: The role of radiation therapy in the management of sarcomas. Surg Clin North Am 88: 629-646, viii, 2008.

4. O'Brien GC, Cahill RA, Bouchier-Hayes DJ and Redmond HP: Co-immunotherapy with interleukin-2 and taurolidine for progressive metastatic melanoma. Ir J Med Sci 175: 10-14, 2006 .

5. Solomon LR, Cheesbrough JS, Bhargava R, Mitsides N, Heap M, Green G and Diggle P: Observational study of need for thrombolytic therapy and incidence of bacteremia using taurolidine-citrate-heparin, taurolidine-citrate and heparin catheter locks in patients treated with hemodialysis. Semin Dial 25: 233-238, 2012.
6. Karavasilis V, Seddon BM, Ashley S, Al-Muderis O, Fisher C and Judson I: Significant clinical benefit of first-line palliative chemotherapy in advanced soft-tissue sarcoma: Retrospective analysis and identification of prognostic factors in 488 patients. Cancer 112: 1585-1591, 2008.

7. Billingsley KG, Lewis JJ, Leung DH, Casper ES, Woodruff JM and Brennan MF: Multifactorial analysis of the survival of patients with distant metastasis arising from primary extremity sarcoma. Cancer 85: 389-395, 1999.

8. Pezzi CM, Pollock RE, Evans HL, Lorigan JG, Pezzi TA, Benjamin RS and Romsdahl MM: Preoperative chemotherapy for soft-tissue sarcomas of the extremities. Ann Surg 211: 476-481, 1990.

9. Donato Di Paola E and Nielsen OS; EORTC Soft Tissue and Bone Sarcoma Group: The EORTC soft tissue and bone sarcoma group. European Organisation for Research and Treatment of Cancer. Eur J Cancer 38: (Suppl 4) S138-S141, 2002.

10. Nedea EA and DeLaney TF: Sarcoma and skin radiation oncology. Hematol Oncol Clin North Am 20: 401-429, 2006.

11. Brodowicz T, Schwameis E, Widder J, Amann G, Wiltschke C, Dominkus M, Windhager R, Ritschl P, Pötter R, Kotz R and Zielinski CC: Intensified adjuvant IFADIC chemotherapy for adult soft tissue sarcoma: A prospective randomized feasibility trial. Sarcoma 4: 151-160, 2000.

12. Frustaci S, Gherlinzoni F, De Paoli A, Bonetti M, Azzarelli A, Comandone A, Olmi P, Buonadonna A, Pignatti G, Barbieri E, et al: Adjuvant chemotherapy for adult soft tissue sarcomas of the extremities and girdles: Results of the Italian randomized cooperative trial. J Clin Oncol 19: 1238-1247, 2001.

13. Judson I, Verweij J, Gelderblom H, Hartmann JT, Schöffski P, Blay JY, Kerst JM, Sufliarsky J, Whelan J, Hohenberger P, et al: Doxorubicin alone versus intensified doxorubicin plus ifosfamide for first-line treatment of advanced or metastatic soft-tissue sarcoma: A randomised controlled phase 3 trial. Lancet Oncol 15: 415-423, 2014

14. Swain SM, Whaley FS and Ewer MS: Congestive heart failure in patients treated with doxorubicin: A retrospective analysis of three trials. Cancer 97: 2869-2879, 2003.

15. Burningham Z, Hashibe M, Spector L and Schiffman JD: The epidemiology of sarcoma. Clin Sarcoma Res 2: 14, 2012.

16. Jiang L, Tao C, He A and He X: Overexpression of miR-126 sensitizes osteosarcoma cells to apoptosis induced by epigallocatechin-3-gallate. World J Surg Oncol 12: 383, 2014.

17. Lambert JD, Sang S, Hong J and Yang CS: Anticancer and anti-inflammatory effects of cysteine metabolites of the green tea polyphenol, (-)-epigallocatechin-3-gallate. J Agric Food Chem 58: 10016-10019, 2010.

18. Kalaiselvi P, Rajashree K, Bharathi Priya L and Padma VV: Cytoprotective effect of epigallocatechin-3-gallate against deoxynivalenol-induced toxicity through anti-oxidative and anti-inflammatory mechanisms in HT-29 cells. Food Chem Toxicol 56: 110-118, 2013.

19. Deng YT and Lin JK: EGCG inhibits the invasion of highly invasive CL1-5 lung cancer cells through suppressing MMP-2 expression via JNK signaling and induces G2/M arrest. J Agric Food Chem 59: 13318-13327, 2011.

20. Kobalka AJ, Keck RW and Jankun J: Synergistic anticancer activity of biologicals from green and black tea on DU 145 human prostate cancer cells. Cent Eur J Immunol 40: 1-4, 2015.

21. Park IJ, Lee YK, Hwang JT, Kwon DY, Ha J and Park OJ: Green tea catechin controls apoptosis in colon cancer cells by attenuation of $\mathrm{H} 2 \mathrm{O} 2$-stimulated COX-2 expression via the AMPK signaling pathway at low-dose H2O2. Ann N Y Acad Sci 1171: 538-544, 2009.

22. Park JS, Khoi PN, Joo YE, Lee YH, Lang SA, Stoeltzing O and Jung YD: EGCG inhibits recepteur d'origine nantais expression by suppressing Egr-1 in gastric cancer cells. Int $\mathrm{J}$ Oncol 42: 1120-1126, 2013

23. Braicu C, Gherman CD, Irimie A and Berindan-Neagoe I: Epigallocatechin-3-Gallate (EGCG) inhibits cell proliferation and migratory behaviour of triple negative breast cancer cells. J Nanosci Nanotechnol 13: 632-637, 2013.

24. Zou C, Liu H, Feugang JM, Hao Z, Chow HH and Garcia F: Green tea compound in chemoprevention of cervical cancer. Int $\mathrm{J}$ Gynecol Cancer 20: 617-624, 2010.

25. Shanafelt TD, Call TG, Zent CS, Leis JF, LaPlant B, Bowen DA, Roos M, Laumann K, Ghosh AK, Lesnick C, et al: Phase 2 trial of daily, oral Polyphenon E in patients with asymptomatic, Rai stage 0 to II chronic lymphocytic leukemia. Cancer 119: 363-370, 2013. 
26. de la Torre R, de Sola S, Hernandez G, Farré M, Pujol J, Rodriguez J, Espadaler JM, Langohr K, Cuenca-Royo A, Principe A, et al: Safety and efficacy of cognitive training plus epigallocatechin-3-gallate in young adults with Down's syndrome (TESDAD): A double-blind, randomised, placebo-controlled, phase 2 trial. Lancet Neurol 15: 801-810, 2016.

27. Zhao H, Xie P, Li X, Zhu W, Sun X, Sun X, Chen X, Xing L and $\mathrm{Yu}$ J: A prospective phase II trial of EGCG in treatment of acute radiation-induced esophagitis for stage III lung cancer. Radiother Oncol 114: 351-356, 2015.

28. Trudel D, Labbé DP, Araya-Farias M, Doyen A, Bazinet L, Duchesne T,Plante M,Grégoire J, Renaud MC,Bachvarov D, et al: A two-stage, single-arm, phase II study of EGCG-enriched green tea drink as a maintenance therapy in women with advanced stage ovarian cancer. Gynecol Oncol 131: 357-361, 2013.

29. Dostal AM, Samavat H, Bedell S, Torkelson C, Wang R, Swenson K, Le C, Wu AH, Ursin G, Yuan JM and Kurzer MS: The safety of green tea extract supplementation in postmenopausal women at risk for breast cancer: Results of the Minnesota Green Tea Trial. Food Chem Toxicol 83: 26-35, 2015.

30. Garcia FA, Cornelison T, Nuño T, Greenspan DL, Byron JW, Hsu CH, Alberts DS and Chow HH: Results of a phase II randomized, double-blind, placebo-controlled trial of Polyphenon E in women with persistent high-risk HPV infection and low-grade cervical intraepithelial neoplasia. Gynecol Oncol 132: 377-382, 2014.

31. Singh BN, Shankar S and Srivastava RK: Green tea catechin, epigallocatechin-3-gallate (EGCG): Mechanisms, perspectives and clinical applications. Biochem Pharmacol 82: 1807-1821, 2011

32. Shanafelt TD, Call TG, Zent CS, LaPlant B, Bowen DA, Roos M, Secreto CR, Ghosh AK, Kabat BF, Lee MJ, et al: Phase I trial of daily oral Polyphenon E in patients with asymptomatic Rai stage 0 to II chronic lymphocytic leukemia. J Clin Oncol 27: 3808-3814, 2009.

33. Mengs U, Pohl RT and Mitchell T: Legalon ${ }^{\circledR}$ SIL: The antidote of choice in patients with acute hepatotoxicity from amatoxin poisoning. Curr Pharm Biotechnol 13: 1964-1970, 2012.

34. Flaig TW, Glodé M, Gustafson D, van Bokhoven A, Tao Y, Wilson S, Su LJ, Li Y, Harrison G, Agarwal R, et al: A study of high-dose oral silybin-phytosome followed by prostatectomy in patients with localized prostate cancer. Prostate 70: 848-855, 2010

35. Flaig TW, Gustafson DL, Su LJ, Zirrolli JA, Crighton F, Harrison GS, Pierson AS, Agarwal R and Glodé LM: A phase I and pharmacokinetic study of silybin-phytosome in prostate cancer patients. Invest New Drugs 25: 139-146, 2007.

36. Kaur M, Velmurugan B, Tyagi A, Deep G, Katiyar S, Agarwal C and Agarwal R: Silibinin suppresses growth and induces apoptotic death of human colorectal carcinoma LoVo cells in culture and tumor xenograft. Mol Cancer Ther 8: 2366-2374, 2009.

37. Singh RP and Agarwal R: Prostate cancer chemoprevention by silibinin: Bench to bedside. Mol Carcinog 45: 436-442, 2006.

38. Leon IE, Porro V, Di Virgilio AL, Naso LG, Williams PA, Bollati-Fogolín M and Etcheverry SB: Antiproliferative and apoptosis-inducing activity of an oxidovanadium (IV) complex with the flavonoid silibinin against osteosarcoma cells. J Biol Inorg Chem 19: 59-74, 2014.

39. Vue B, Zhang S, Zhang X, Parisis K, Zhang Q, Zheng S, Wang $\mathrm{G}$ and Chen QH: Silibinin derivatives as anti-prostate cancer agents: Synthesis and cell-based evaluations. Eur J Med Chem 109: 36-46, 2016

40. Duan WJ, Li QS, Xia MY, Tashiro S, Onodera S and Ikejima T: Silibinin activated p53 and induced autophagic death in human fibrosarcoma HT1080 cells via reactive oxygen species-p38 and c-Jun N-terminal kinase pathways. Biol Pharm Bull 34: 47-53, 2011.

41. Ghaly PE, Abou El-Magd RM, Churchill CD, Tuszynski JA and West FG: A new antiproliferative noscapine analogue: Chemical synthesis and biological evaluation. Oncotarget 7: 40518-40530, 2016.

42. Yang ZR, Liu M, Peng XL, Lei XF, Zhang JX and Dong WG: Noscapine induces mitochondria-mediated apoptosis in human colon cancer cells in vivo and in vitro. Biochem Biophys Res Commun 421: 627-633, 2012

43. Li S, He J, Li S, Cao G, Tang S, Tong Q and Joshi HC: Noscapine induced apoptosis via downregulation of survivin in human neuroblastoma cells having wild type or null p53. PloS One 7: e40076, 2012.

44. Quisbert-Valenzuela EO and Calaf GM: Apoptotic effect of noscapine in breast cancer cell lines. Int J Oncol 48: 2666-2674, 2016.
45. Lopus $M$ and Naik PK: Taking aim at a dynamic target: Noscapinoids as microtubule-targeted cancer therapeutics. Pharmacol Rep 67: 56-62, 2015.

46. Mukkavilli R, Gundala SR, Yang C, Jadhav GR, Vangala S, Reid MD and Aneja R: Noscapine recirculates enterohepatically and induces self-clearance. Eur J Pharm Sci 77: 90-99, 2015.

47. Stratford EW, Castro R, Daffinrud J, Skårn M, Lauvrak S, Munthe E and Myklebost O: Characterization of liposarcoma cell lines for preclinical and biological studies. Sarcoma 2012: 148614, 2012.

48. Aman P, Ron D, Mandahl N, Fioretos T, Heim S, Arheden K, Willén H, Rydholm A and Mitelman F: Rearrangement of the transcription factor gene CHOP in myxoid liposarcomas with $\mathrm{t}(12 ; 16)(\mathrm{q} 13 ; \mathrm{p} 11)$. Genes, chromosomes cancer 5: 278-285, 1992.

49. Kawai A, Naito N, Yoshida A, Morimoto Y, Ouchida M, Shimizu K and Beppu Y: Establishment and characterization of a biphasic synovial sarcoma cell line, SYO-1. Cancer Lett 204: 105-113, 2004

50. Xie Y, Skytting B, Nilsson G, Gasbarri A, Haslam K, Bartolazzi A, Brodin B, Mandahl N and Larsson O: SYT-SSX is critical for cyclin D1 expression in synovial sarcoma cells: A gain of function of the $t(X ; 18)(p 11.2 ; q 11.2)$ translocation. Cancer Res 62: 3861-3867, 2002.

51. Becerikli M, Jacobsen F, Rittig A, Köhne W, Nambiar S, Mirmohammadsadegh A, Stricker I, Tannapfel A, Wieczorek S, Epplen JT, et al: Growth rate of late passage sarcoma cells is independent of epigenetic events but dependent on the amount of chromosomal aberrations. Exp Cell Res 319: 1724-1731, 2013.

52. Kang HG, Jenabi JM, Liu XF, Reynolds CP, Triche TJ and Sorensen PH: Inhibition of the insulin-like growth factor I receptor by epigallocatechin gallate blocks proliferation and induces the death of Ewing tumor cells. Mol Cancer Ther 9: 1396-1407, 2010

53. Chougule MB, Patel AR, Jackson T and Singh M: Antitumor activity of Noscapine in combination with Doxorubicin in triple negative breast cancer. PloS One 6: e17733, 2011.

54. Koval OA, Sakaeva GR, Fomin AS, Nushtaeva AA, Semenov DV, Kuligina EV, Gulyaeva LF, Gerasimov AV and Richter VA: Sensitivity of endometrial cancer cells from primary human tumor samples to new potential anticancer peptide lactaptin. J Cancer Res Ther 11: 345-351, 2015.

55. Italiano A, Toulmonde M, Cioffi A, Penel N, Isambert N, Bompas E, Duffaud F, Patrikidou A, Lortal B, Le Cesne A, et al: Advanced well-differentiated/dedifferentiated liposarcomas: Role of chemotherapy and survival. Ann Oncol 23: 1601-1607, 2012.

56. Italiano A, Garbay D, Cioffi A, Maki RG and Bui B: Advanced pleomorphic liposarcomas: Clinical outcome and impact of chemotherapy. Ann Oncol 23: 2205-2206, 2012.

57. Jones RL, Fisher C, Al-Muderis O and Judson IR: Differential sensitivity of liposarcoma subtypes to chemotherapy. Eur J Cancer 41: 2853-2860, 2005.

58. Patel SR, Burgess MA, Plager C, Papadopoulos NE, Linke KA and Benjamin RS: Myxoid liposarcoma. Experience with chemotherapy. Cancer 74: 1265-1269, 1994.

59. Vlenterie M, Litière S, Rizzo E, Marréaud S, Judson I, Gelderblom H, Le Cesne A, Wardelmann E, Messiou C, Gronchi A and van der Graaf WT: Outcome of chemotherapy in advanced synovial sarcoma patients: Review of 15 clinical trials from the European Organisation for Research and Treatment of Cancer Soft Tissue and Bone Sarcoma Group; setting a new landmark for studies in this entity. Eur J Cancer 58: 62-72, 2016

60. Saeed NM, El-Naga RN, El-Bakly WM, Abdel-Rahman HM, Salah ElDin RA and El-Demerdash E: Epigallocatechin-3-gallate pretreatment attenuates doxorubicin-induced cardiotoxicity in rats: A mechanistic study. Biochem Pharmacol 95: 145-155, 2015.

61. Khan MA, Singh M, Khan MS, Ahmad W, Najmi AK and Ahmad S: Alternative approach for mitigation of doxorubicin-induced cardiotoxicity using herbal agents. Curr Clin Pharmacol 9: 288-297, 2014.

62. Zheng J, Lee HC, Bin Sattar MM, Huang Y and Bian JS Cardioprotective effects of epigallocatechin-3-gallate against doxorubicin-induced cardiomyocyte injury. Eur J Pharmacol 652: 82-88, 2011.

63. Li W, Nie S, Xie M, Chen Y, Li C and Zhang H: A major green tea component, (-)-epigallocatechin-3-gallate, ameliorates doxorubicin-mediated cardiotoxicity in cardiomyocytes of neonatal rats. J Agric Food Chem 58: 8977-8982, 2010. 
64. Cheng T, Liu J, Ren J, Huang F, Ou H, Ding Y, Zhang Y, Ma R, An Y, Liu J and Shi L: Green tea catechin-based complex micelles combined with doxorubicin to overcome cardiotoxicity and multidrug resistance. Theranostics 6: 1277-1292, 2016.

65. Stearns ME, Amatangelo MD, Varma D, Sell C and Goodyear SM: Combination therapy with epigallocatechin-3-gallate and doxorubicin in human prostate tumor modeling studies: Inhibition of metastatic tumor growth in severe combined immunodeficiency mice. Am J Pathol 177: 3169-3179, 2010.

66. Chen L, Ye HL, Zhang G, Yao WM, Chen XZ, Zhang FC and Liang G: Autophagy inhibition contributes to the synergistic interaction between EGCG and doxorubicin to kill the hepatoma Hep3B cells. PloS One 9: e85771, 2014.

67. Liang G, Tang A, Lin X, Li L, Zhang S, Huang Z, Tang H and Li QQ: Green tea catechins augment the antitumor activity of doxorubicin in an in vivo mouse model for chemoresistant liver cancer. Int J Oncol 37: 111-123, 2010.

68. Singh RP, Mallikarjuna GU, Sharma G, Dhanalakshmi S, Tyagi AK, Chan DC, Agarwal C and Agarwal R: Oral silibinin inhibits lung tumor growth in athymic nude mice and forms a novel chemocombination with doxorubicin targeting nuclear factor kappaB-mediated inducible chemoresistance. Clin Cancer Res 10: 8641-8647, 2004.
69. Tyagi AK, Agarwal C, Chan DC and Agarwal R: Synergistic anti-cancer effects of silibinin with conventional cytotoxic agents doxorubicin, cisplatin and carboplatin against human breast carcinoma MCF-7 and MDA-MB468 cells. Oncol Rep 11: 493-499, 2004

70. Tyagi AK, Singh RP, Agarwal C, Chan DC and Agarwal R: Silibinin strongly synergizes human prostate carcinoma DU145 cells to doxorubicin-induced growth Inhibition, G2-M arrest, and apoptosis. Clin Cancer Res 8: 3512-3519, 2002.

71. Rašković A, Stilinović N, Kolarović J, Vasović V, Vukmirović S and Mikov M: The protective effects of silymarin against doxorubicin-induced cardiotoxicity and hepatotoxicity in rats. Molecules 16: 8601-8613, 2011

72. Chlopcíková S, Psotová J, Miketová P and Simánek V: Chemoprotective effect of plant phenolics against anthracycline-induced toxicity on rat cardiomyocytes. Part I. Silymarin and its flavonolignans. Phytother Res: 18: 107-110, 2004.

73. Psotová J, Chlopcíková S, Grambal F, Simánek V and Ulrichová J: Influence of silymarin and its flavonolignans on doxorubicin-iron induced lipid peroxidation in rat heart microsomes and mitochondria in comparison with quercetin. Phytother Res 16: (Suppl 1) S63-S67, 2002. 